\title{
pH-Controlled fluorescence switching in water-dispersed polymer brushes grafted to modified boron nitride nanotubes for cellular imaging
}

\author{
Saban Kalay ${ }^{1}$, Yurij Stetsyshyn*2, Volodymyr Donchak², Khrystyna Harhay ${ }^{2}$, \\ Ostap Lishchynskyi ${ }^{2}$, Halyna Ohar ${ }^{2}$, Yuriy Panchenko ${ }^{2}$, Stanislav Voronov ${ }^{2}$ \\ and Mustafa Çulha ${ }^{1}$
}

\author{
Full Research Paper \\ Address: \\ 1Department of Genetics and Bioengineering, Yeditepe University, \\ Atasehir, 34755 Istanbul, Turkey and ${ }^{2}$ Lviv Polytechnic National \\ University, 12 S. Bandery, 79013 Lviv, Ukraine \\ Email: \\ Yurij Stetsyshyn* - yrstecushun@ukr.net \\ * Corresponding author \\ Keywords: \\ boron nitride nanotubes; cellular imaging; fluorescence; $\mathrm{pH}$ switching; \\ polymer brushes; surface modification
}

Beilstein J. Nanotechnol. 2019, 10, 2428-2439. doi:10.3762/bjnano.10.233

Received: 16 September 2019

Accepted: 07 November 2019

Published: 10 December 2019

Associate Editor: A. Gölzhäuser

(c) 2019 Kalay et al.; licensee Beilstein-Institut. License and terms: see end of document.

\begin{abstract}
pH-Switchable, fluorescent, hybrid, water-dispersible nanomaterials based on boron nitride nanotubes (BNNTs) and grafted copolymer brushes (poly(acrylic acid-co-fluorescein acrylate) - P(AA-co-FA)) were successfully fabricated in a two-step process. The functionalization of BNNTs was confirmed by spectroscopic, gravimetric and imaging techniques. In contrast to "pure" BNNTs, P(AA-co-FA)-functionalized BNNTs demonstrate intense green fluorescence emission at $520 \mathrm{~nm}$. Under neutral or alkaline $\mathrm{pH}$ values, $\mathrm{P}(\mathrm{AA}-\mathrm{co}-\mathrm{FA})$-functionalized BNNTs are highly emissive in contrast to acidic $\mathrm{pH}$ conditions where the fluorescent intensity is absent or low. No increase in the absorption was observed when the suspension $\mathrm{pH}$ was increased from 7 to 10 . The functionalized BNNTs are easily taken up by human normal prostate epithelium (PNT1A) and human prostate cancer cell lines (DU145) and are suitable for further evaluation in cellular imaging applications.
\end{abstract}

\section{Introduction}

In recent years, considerable effort has been devoted to the development of hybrid nanomaterials [1-5] to generate novel structures with tunable properties through external stimuli such as $\mathrm{pH}$, temperature, light, and magnetic field [6-10]. Among other nanomaterials, significant research effort has been dedicated to the use of nanotubes [1-4,6,7,11-16]. For the last two decades, carbon nanotubes [17], such as metal nanotubes [18], oxide nanotubes [19], boron nitride nanotubes (BNNTs) [12] and nanotubular clays $[6,7]$ were intensively studied. The reason behind the widespread interest in nanotubes is due to their excellent application potential in several fields [1-4,6,7,1116]. BNNTs were first synthesized by Chopra et al. [20] in 1995 
and they are considered as the structural analog to CNTs. BNNTs are of particular interest due to their remarkable mechanical properties (e.g., Young's modulus of 1.22 TPa) and low toxicity [21-24]. They are superhydrophobic in their pristine state and cannot be dispersed in aqueous media or in most organic solvents $[11,22,23]$. To improve the dispersibility of BNNTs in aqueous media, numerous surface functionalization methods have been used [11,25-27]. The functionalization strategies can be classified into three groups: (1) noncovalent, (2) covalent grafting to the surface, and (3) formation of amino and/or hydroxyl groups at the ends and defect sites [11,25-27]. Up to now, the most prospective procedure for BNNT functionalization is covalent grafting of polymer brushes via polymerization initiated from their surface $[12,28]$. In particular, BNNTs were covalently modified with hydrophobic polystyrene or poly(glycidyl methacrylate) polymer brushes [28]. The modified nanotubes demonstrated high dispersibility in a large number of organic solvents. In our previous work [12], BNNTs were functionalized with thermo-responsive poly- $N$-isopropylacrylamide (PNIPAM) and became dispersible in water. The hydrodynamic radius of PNIPAM-modified BNNTs was decreased two-fold at temperatures above $32{ }^{\circ} \mathrm{C}$. Along with other nanomaterials, the various nanotubes were tested as fluorescent probes for a number of bio-responsive applications, ranging from drug delivery to genomics [29-31]. Similar to other nanotubes, the pristine BNNTs were not fluorescent, and a fluorophore (e.g., organic molecule or quantum dot) is added via surface modification to make them fluorescent [29-34].

In [35], the fluorescent CdSe quantum dots were attached to BNNT surfaces, and in [36] the halloysite nanotubes were modified with carbon dots and used for cellular imaging. Another approach is surface modification with grafted polymers bearing organic fluorophores. One of the most commonly used labels is fluorescein [37-42]. In biomedical applications, fluorescein has several advantages over other dyes such as nontoxicity, high water solubility, and $\mathrm{pH}$ responsivity. Fluorescein demonstrates a high fluorescence efficiency at basic $\mathrm{pH}$ values but becomes nonfluorescent under acidic conditions [42].

In our previous work [12], we have reported a two-step method for preparation of a responsive surface layer on oligoperoxidefunctionalized BNNTs, where amino groups on BNNTs form at the ends and defects. Additional amine groups can be easily introduced with ammonia plasma irradiation [43], by mechanical milling [44] or with the iminoborane treatment [45]. The first step in covalent bonding of oligoperoxide to BNNT surfaces is to bind pyromellitic chloroanhydride moieties through available amino groups. The second step involves the grafting polymerization "from the surface" of oligoperoxide-functionali- zed BNNTs. With this procedure, we have created a hybrid nanomaterial for cellular imaging based on BNNTs and grafted brushes of $\mathrm{pH}$-responsive fluorescent copolymer poly(acrylic acid-co-fluorescein acrylate) - $\mathrm{P}(\mathrm{AA}-\mathrm{co}$-FA). The functionalization of BNNTs was studied with thermogravimetric analysis (TGA), Fourier transform infrared spectroscopy (FTIR), dynamic light scattering (DLS), ultraviolet-visible spectrophotometry (UV-vis), laser scanning confocal microscopy (LSCM) and scanning electron microscopy (SEM). The DLS results demonstrated that P(AA-co-FA)-functionalized BNNTs exhibited good dispersibility in water. $\mathrm{pH}$-Controlled switching of fluorescence was demonstrated using LSCM and UV-vis. In addition, the potential of BNNTs as novel $\mathrm{pH}$-switchable fluorescent water-dispersible materials for cellular imaging has been investigated. The developed hybrid structure can potentially be used not only for cellular imaging but also as "smart" surfaces, nanotransducers and nanocarriers.

\section{Experimental Materials}

Pyridine and other organic solvents were purified as reported by Riddick et al. [46]. Poly(ethylene glycol) (PEG-9) was supplied by Merck Chemical Co.; acrylic acid and fluorescein acrylate were supplied by Sigma-Aldrich. Colemanite $\left(\mathrm{Ca}_{2} \mathrm{~B}_{6} \mathrm{O}_{11} \cdot 5 \mathrm{H}_{2} \mathrm{O}\right)$ was obtained from ETI Mine Works General Management (Turkey). Iron(III) oxide, hydrochloric acid, and nitric acid were purchased from Sigma-Aldrich. Highly pure $\mathrm{NH}_{3}$ gas (99.98\%) was provided by Schick GmbH \& Co. KG. All solutions were prepared with distilled water.

\section{Synthesis}

\section{Synthesis of tert-butyl hydroperoxide}

tert-Butyl hydroperoxide was obtained as described in [47] and purified by vacuum rectification. The fraction, boiled in the temperature range of $45-47{ }^{\circ} \mathrm{C}$ (at $1.6 \mathrm{kPa}$ ), was collected. Its refractive index was determined to be $n_{\mathrm{d}}{ }^{20}=1.40020 \pm 0.00002$, which is in agreement with values reported elsewhere $\left(n_{\mathrm{d}}{ }^{20}=1.4010\right)$ [47].

\section{Synthesis of pyromellitic acid chloride}

As described in [12], in a $500 \mathrm{~mL}$ round-bottomed flask equipped with a thermometer and a reflux condenser connected with water scrubber, $43.6 \mathrm{~g}(0.2 \mathrm{~mol})$ of pyromellitic dianhydride and $91.6 \mathrm{~g}(0.44 \mathrm{~mol})$ of $\mathrm{PCl}_{5}$ were mixed and boiled in the oil bath until the mixture became homogeneous. The mixture was stirred at $130-135{ }^{\circ} \mathrm{C}$ for $15-16 \mathrm{~h}$. Then, the reflux condenser was replaced by a Liebig condenser, and approximately $60-63 \mathrm{~g}$ of $\mathrm{POCl}_{3}$ was distilled out during $8 \mathrm{~h}$. At the end of the distillation, the temperature of the mixture was increased up to $180-185^{\circ} \mathrm{C}$ for $1 \mathrm{~h}$. The crude product was recrystallized from gasoline, yielding $51.2 \mathrm{~g}$ (78.1\%) of a color- 
less crystalline product with the melting point of $67{ }^{\circ} \mathrm{C}$ (literature value $68{ }^{\circ} \mathrm{C}$ ) [48] and the acid number $\mathrm{AN}=1373 \mathrm{mg} \mathrm{KOH} / \mathrm{g}$ (theoretical value is $1368 \mathrm{mg} \mathrm{KOH} / \mathrm{g}$ ).

\section{Synthesis of oligoperoxide with residual acid chloride groups}

As described in [12], $4.6 \mathrm{~g}$ (0.014 mol) of pyromellitic acid chloride was dissolved in $15 \mathrm{~mL}$ of anhydrous dichloroethane, placed in a three-necked flask equipped with a stirrer and $1.26 \mathrm{~g}$ $(0.014 \mathrm{~mol})$ of tert-butyl hydroperoxide was added. The mixture was cooled down to $5{ }^{\circ} \mathrm{C}$ and then $1.1 \mathrm{~g}(0.014 \mathrm{~mol})$ of pyridine, dissolved in $10 \mathrm{~mL}$ of anhydrous dichloroethane, was added dropwise at $5{ }^{\circ} \mathrm{C}$. The suspension was stirred for $1 \mathrm{~h}$. Subsequently, $5.6 \mathrm{~g}$ (0.014 mol) of PEG-9 was added, and again the solution of $2.2 \mathrm{~g}(0.028 \mathrm{~mol})$ pyridine in $10 \mathrm{~mL}$ of anhydrous dichloroethane was admixed dropwise. The mixture was then stirred for another $3 \mathrm{~h}$, and the temperature was increased gradually to ambient temperature. The pyridinium chloride precipitate was filtered out. The solvent was distilled out and the pellet was dried in vacuum $(100-200 \mathrm{~Pa})$ at $40{ }^{\circ} \mathrm{C}$ for $3 \mathrm{~h}$, yielding $8.2 \mathrm{~g}(81 \%)$ of oligoperoxide. Its characteristics are summarized as follows: content of active oxygen $-1.9 \%$ (calc. 2.2\%); content of active chlorine $-5.4 \%$ (calc. $4.9 \%$ ); $\mathrm{AN}=163.1 \mathrm{mg} \mathrm{KOH} / \mathrm{g}$ (calc. $155.3 \mathrm{mg} \mathrm{KOH} / \mathrm{g}$ ); characteristic infrared spectra bands $-v(\mathrm{C}=\mathrm{O})$ in $\mathrm{Ar}-\mathrm{C}(\mathrm{O}) \mathrm{Cl}, v(\mathrm{C}=\mathrm{O})$ in ester group at 1760 and $1752 \mathrm{~cm}^{-1}$; doublet at 1390 ,

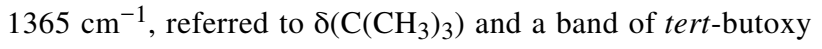
group at $848 \mathrm{~cm}^{-1}$.

\section{BNNT synthesis and purification}

The BNNTs were synthesized by chemical vapor deposition from colemanite (2 g) and $\mathrm{Fe}_{2} \mathrm{O}_{3}(0.166 \mathrm{~g})$ [25]. Briefly, the precursor mixture was transferred to an alumina boat and preheated at $180{ }^{\circ} \mathrm{C}$ for $15 \mathrm{~min}$ and then the alumina boat was placed into the center of the tubular furnace (Protherm, Furnaces PTF 14/50/450). The BNNT synthesis was performed under saturated $\mathrm{NH}_{3}$ atmosphere. The furnace temperature was set to a heating rate of $8{ }^{\circ} \mathrm{C} / \mathrm{min}$ up to $1280{ }^{\circ} \mathrm{C}$ and then held at this temperature for $3 \mathrm{~h}$. The furnace was cooled down to ambient temperature. Thereafter, the BNNTs were collected from the top of the alumina boat and stored in a dry environment.

For the purification, the obtained BNNTs were added to $50 \mathrm{~mL}$ $4 \mathrm{M} \mathrm{HCl}$, stirred for $4 \mathrm{~h}$ at $90^{\circ} \mathrm{C}$ and then collected by centrifugation (14000 rpm, $30 \mathrm{~min}$ ). The obtained product was stirred in $30 \mathrm{~mL}$ of $1 \mathrm{M} \mathrm{HNO}_{3}$ for $6 \mathrm{~h}$ at $30{ }^{\circ} \mathrm{C}$ and was then collected by centrifugation at $14000 \mathrm{rpm}$ for $30 \mathrm{~min}$. After the centrifugation, the BNNTs were washed with distilled water until all acid was removed and were then dried at $60{ }^{\circ} \mathrm{C}$ overnight.

\section{Modification of BNNTs Modification of BNNTs with oligoperoxide}

The modification procedure of BNNTs is presented below in Scheme 1. As described in [12], $50 \mathrm{mg}$ of powdered BNNTs (1) were mixed with $50 \mathrm{~mL}$ of oligoperoxide solution in anhydrous dioxane $(1 \mathrm{mg} / \mathrm{mL})$ and sonicated for $20 \mathrm{~min}$ after the solution was stirred vigorously for $24 \mathrm{~h}$. The excess of oligoperoxide was removed by repeated dispersion with sonication into dioxane and toluene and collection of the nanotubes by centrifugation. The purified oligoperoxide-functionalized BNNTs were dried and used for grafting polymerization (2).

\section{Fabrication of $\mathrm{P}(\mathrm{AA}-\mathrm{CO}-\mathrm{FA})$-grafted brushes}

BNNTs with grafted oligoperoxide [(2) below in Scheme 1] were placed in a container with $0.1 \mathrm{M}$ of AA and $0.01 \mathrm{M}$ FA aqueous solution and sonicated for $20 \mathrm{~min}$. Then, the mixture was heated under argon atmosphere to $90{ }^{\circ} \mathrm{C}$ for $48 \mathrm{~h}$, resulting in the $\mathrm{P}(\mathrm{AA}-\mathrm{co}$-FA)-graft-oligoperoxide functionalized BNNTs (3). These were purified by repeated dispersed in ethanol and water with sonication and collection of the nanotubes by centrifugation. The purified $\mathrm{P}(\mathrm{AA}-\mathrm{co}$-FA)-graft-oligoperoxide functionalized BNNTs were dried and stored as a powder.

\section{Characterization of BNNTs Thermogravimetric analysis (TGA)}

TGA analysis was performed using a Perkin Elmer Pyris 1 TGA instrument with Thermal Analysis Gas Station and Pyris Version 11.1.1.0497 software. The samples were analyzed under $\mathrm{N}_{2}$ gas flow, which was heated from 30.00 to $600.00{ }^{\circ} \mathrm{C}$ at $10{ }^{\circ} \mathrm{C} / \mathrm{min}$.

\section{Fourier transform infrared spectroscopy (FTIR)}

FTIR spectra were recorded on a NICOLET iS50 FTIR spectrometer (Thermo Scientific, USA), equipped with a iS50 ATR multirange, diamond sampling station. The sample powders were either placed on diamond crystal or mixed with $\mathrm{KBr}$ to form a pellet. The spectra in the range of $7800-350 \mathrm{~cm}^{-1}$ with a $5 \mathrm{~cm}^{-1}$ step were collected in reflection or in transmission mode.

\section{Laser scanning confocal microscopy (LSCM)}

$\mathrm{P}$ (AA-co-FA)-functionalized BNNTs were imaged with a Zeiss Axio Imager M2 laser scanning confocal microscope (Carl Zeiss Microimaging GmbH, Zeiss, Jena, Germany), equipped with the following optical elements: Zeiss 5×/0.16 EC PlanNEOFLUAR, Zeiss $10 \times / 0.13$ EC Plan-NEOFLUAR, Zeiss $20 \times / 0.8$ Plan-Apochromat, Zeiss $40 \times / 0.95$ Kor, Zeiss $63 \times / 1.4$ oil DIC Plan-Apochromat and Zeiss $100 \times / 1.4$ oil DIC PlanApochromat. In our study the excitation and emission wavelengths were selected at $490 \mathrm{~nm}$ and $520 \mathrm{~nm}$, respectively, and the fluorescently labeled nanomaterial was viewed. 


\section{Ultraviolet-visible spectrometry (UV-vis)}

The optical absorption spectra of the BNNT suspension were registered on a double-beam UV-vis spectrophotometer (Lambda 35, PerkinElmer, Germany) by scanning in the range of 300-900 nm at room temperature. Prior to the measurement, the baseline was recorded for a cuvette with pure solvent. The nanotube concentration was $1 \mathrm{mg} / \mathrm{mL}$, and the $\mathrm{pH}$ was adjusted by adding $\mathrm{HCl}$ or $\mathrm{NaOH}$.

\section{Fluorescence spectrophotometry}

Fluorescence emission spectra were recorded on a Varian Eclipse spectrophotometer using a $1 \mathrm{~cm}$ path length cuvette at room temperature. The excitation and emission were scanned simultaneously at wavelengths from 200 to $600 \mathrm{~nm}$ and from 220 to $600 \mathrm{~nm}$, respectively, at $5 \mathrm{~nm}$ intervals, with a $5 \mathrm{~nm}$ slit width at a $9600 \mathrm{~nm} / \mathrm{min}$ scan rate. The excitation and emission wavelength and the maximum fluorescence intensity of each peak were recorded. The concentration of BNNTs was $1 \mathrm{mg} / \mathrm{mL}$. The $\mathrm{pH}$ of the suspension was adjusted by adding $\mathrm{HCl}$ or $\mathrm{NaOH}$.

\section{Dynamic light scattering (DLS)}

The size distribution and zeta potential measurements of the nanotubes were performed with a Zetasizer Nano ZS device (Malvern, USA) at $25{ }^{\circ} \mathrm{C}$. The Nano ZS contains a $4 \mathrm{~mW}$ $\mathrm{He}-\mathrm{Ne}$ laser operating at a wavelength of $633 \mathrm{~nm}$ and an avalanche photodiode detector. The scattered light was detected at an angle of $173^{\circ}$. The refractive index and absorption of the nanomaterial were assumed to be 2.0 and 1.500 , respectively. All size and zeta potential measurements were carried out in triplicate. All data were analyzed by using Malvern Instrument DST 5.00 software. $1 \mathrm{mg}$ of sample was suspended in $1 \mathrm{~mL}$ of distilled water and sonicated for 2-10 min. After the sonication, low speed $\left(1000 \mathrm{~g}, 5 \mathrm{~min}, 25^{\circ} \mathrm{C}\right)$ centrifugation was carried out and the supernatant (see below Figure 1) was used for analysis.

\section{Scanning electron microscopy (SEM)}

The BNNTs were placed on a carbon disc and coated with a $5 \mathrm{~nm}$ thick gold layer using a Baltec SDC 005 sputter coater. SEM images were obtained with a Carl Zeiss Evo-40 instrument under high vacuum and accelerating voltage of $10 \mathrm{kV}$.

\section{Cell culture experiments}

Normal prostate epithelium (PNT1A) and human prostate cancer (DU145) cell lines were grown in Dulbecco's Modified Eagle's Medium, supplemented with $10 \%$ fetal bovine serum and $1 \%$ penicillin/streptomycin/ampicillin and incubated in a water-jacketed incubator in a $5 \% \mathrm{CO}_{2}, 95 \%$ air atmosphere at $37{ }^{\circ} \mathrm{C}$. The cells were expanded in T-75 flasks to $80 \%$ confluence and then detached with trypsin and collected. A $1 \mathrm{mg} / \mathrm{mL}$ sample of $\mathrm{P}(\mathrm{AA}-c o-\mathrm{FA})$-functionalized BNNTs dispersed in ultrapure water was used in cellular uptake studies. The cells were imaged with a Zeiss Axio Imager.M2 instrument at an excitation wavelength of $490 \mathrm{~nm}$ and emission of $520 \mathrm{~nm}$.

\section{Results and Discussion \\ Fabrication and properties of fluorescent boron nitride nanotubes}

The $\mathrm{pH}$-responsive fluorescent coatings were formed on the BNNT surface via a simple two-step process as outlined in Scheme 1 and described in detail in the Experimental section. The first step: a multifunctional radical initiator (oligoperoxide) was grafted to the BNNT surface by means of interaction of amino groups (at the defects on the BNNT surface) with chloroanhydride fragments in oligoperoxide molecules [12]. The second step involved grafting copolymerization of acrylic acid and fluorescein acrylate initiating "from the surface" of oligoperoxide-functionalized BNNTs to fabricate grafted polymer brushes.

The functionalized BNNTs were characterized using spectroscopic, gravimetric and imaging techniques including FTIR, UV-vis, DLS, TGA, LSCM and SEM. The fabrication of the oligoperoxide-functionalized BNNTs was described in detail in our previous publication [12] and here we focus on the synthesis and properties of the P(AA-co-FA)-functionalized BNNTs. The functionalized BNNTs after the copolymerization of acrylic acid and fluorescein acrylate has demonstrated an excellent dispersibility in water (Figure 1b) forming a suspension with a light-yellow color without the formation of any visible aggregates. In contrast, native BNNTs are not dispersed at all and white aggregates are visible on the top of the suspension and at the sides of the cuvette (Figure 1a).

To confirm the chemical modification and to isolate oligoperoxide and $\mathrm{P}(\mathrm{AA}-\mathrm{co}-\mathrm{FA})$-graft-functionalized BNNTs from physically adhered polymers, several cycles of centrifugation/ decanting/redispersion in different solvents and water were repeated (see Experimental part).

Figure 2 shows the TGA curves of native BNNTs (a), and oligoperoxide-functionalized BNNTs (b) and P(AA-co-FA)functionalized BNNTs. The weight loss of oligoperoxide-functionalized BNNTs (Figure 2, curves b) is relatively low and is only a few percent. In contrast, P(AA-co-FA)-functionalized BNNTs demonstrate substantial mass loss that is nearly $60 \%$. $\mathrm{P}(\mathrm{AA}-\mathrm{co}$-FA)-functionalized BNNTs exhibit a middle thermal stability around $180{ }^{\circ} \mathrm{C}$ and drastic degradation from 180 to $550{ }^{\circ} \mathrm{C}$. A low concentration of the oligoperoxide macromolecules covalently grafted to BNNTs suggests that not all oligoperoxide macromolecules covalently bound and some remain electrostatically attached to the nanotube surface and are 


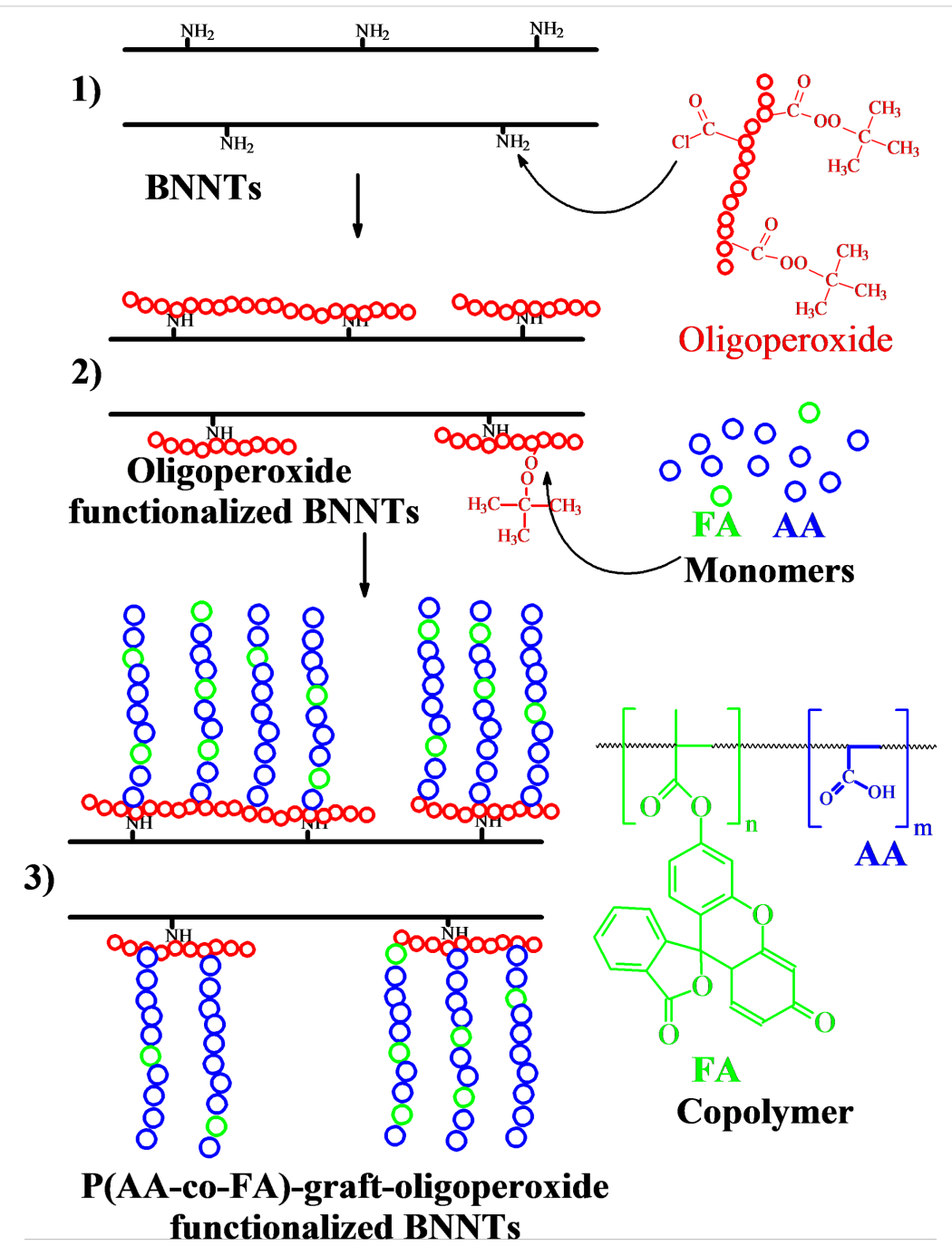

Scheme 1: BNNT (1) functionalization with oligoperoxide (2), and subsequent grafting copolymerization of acrylic acid (AA) and fluorescein acrylate (FA) (3), initiated by peroxide groups of oligoperoxide and resulting in $\mathrm{P}(\mathrm{AA}-\mathrm{co}-\mathrm{FA})$-functionalized BNNTs.

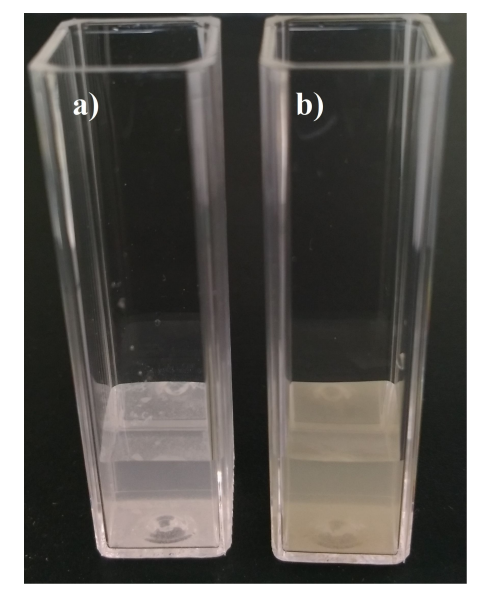

Figure 1: Suspensions of native BNNTs (a) and P(AA-co-FA)-functionalized BNNTs (b) obtained at a concentration of $1 \mathrm{mg} / \mathrm{mL}$ in distilled water after 2 min of sonic bath treatment.

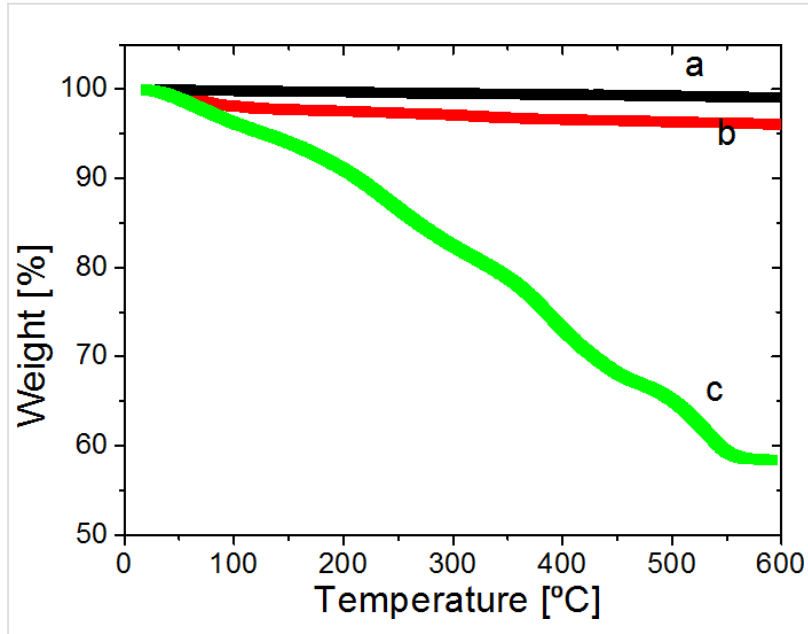

Figure 2: TGA curves of pristine BNNTs (a), oligoperoxide-functionalized BNNTs (b) and P(AA-co-FA)-functionalized BNNTs (c). 
washed off during the functionalization procedure. It also suggests that $\mathrm{P}(\mathrm{AA}-\mathrm{co}-\mathrm{FA})$-grafted brushes grow vertically from the surface of the BNNTs functionalized by oligoperoxide.

The recorded FTIR spectra of pristine and P(AA-co-FA)-functionalized BNNTs are presented in Figure 3. The spectrum of pristine BNNTs is comprised of two broad asymmetric absorp-

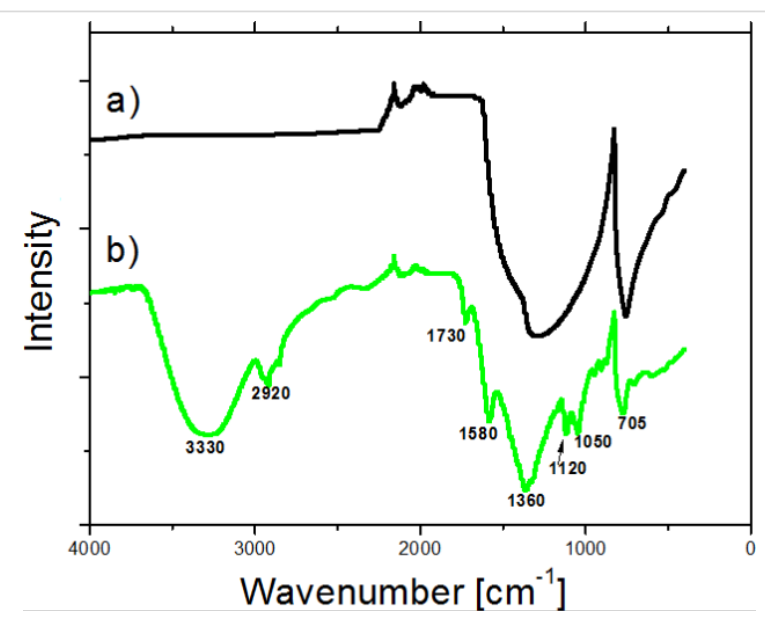

Figure 3: FTIR spectrum of pure BNNT (a) and P(AA-co-FA)-functionalized BNNTs (b) tion bands, the B-N-B longitudinal in-plane bond vibration at $1327 \mathrm{~cm}^{-1}$, and the out-of-plane radial buckling of $\mathrm{B}$ and $\mathrm{N}$ atoms at $758 \mathrm{~cm}^{-1}$ (Figure 3a, black line), which is in full agreement with an earlier report. The FTIR spectra of oligoperoxide-modified BNNTs was described in detail in our previous paper [12] and is not discussed here. After the fabrication of the $\mathrm{P}(\mathrm{AA}-\mathrm{co}-\mathrm{FA})$-functionalized BNNTs, a number of new bands, originating from grafted $\mathrm{P}(\mathrm{AA}-\mathrm{co}-\mathrm{FA})$ fragments, were revealed. New absorption bands at $1327 \mathrm{~cm}^{-1}$ and $758 \mathrm{~cm}^{-1}$ were observed. A broad absorption band at $3330 \mathrm{~cm}^{-1}$ is assigned to the - $\mathrm{OH}$ group of fluorescein acrylate and acrylic acid. Another band at $2920 \mathrm{~cm}^{-1}$ is attributed to stretching vibrations of $\mathrm{C}-\mathrm{H}$ bonds. The absorption band at $1730 \mathrm{~cm}^{-1}$ is formed by carbonyl fragment in carboxyl and ester groups of the fluorescein and acrylic acid. A characteristic peak of benzene rings of fluorescein acrylate appears at around $1580 \mathrm{~cm}^{-1}$. In addition, the $\mathrm{C}-\mathrm{O}-\mathrm{C}$ bonds in esteric fragments are revealed by the stretching vibrations at 1120 and $1050 \mathrm{~cm}^{-1}$. All of this spectral information confirms the successful fabrication of grafted $\mathrm{P}(\mathrm{AA}-\mathrm{co}$-FA) brushes on oligoperoxide-functionalized BNNTs.

The optical properties of P(AA-co-FA)-functionalized BNNTs were studied by absorption and confocal microscopy. Figure 4a
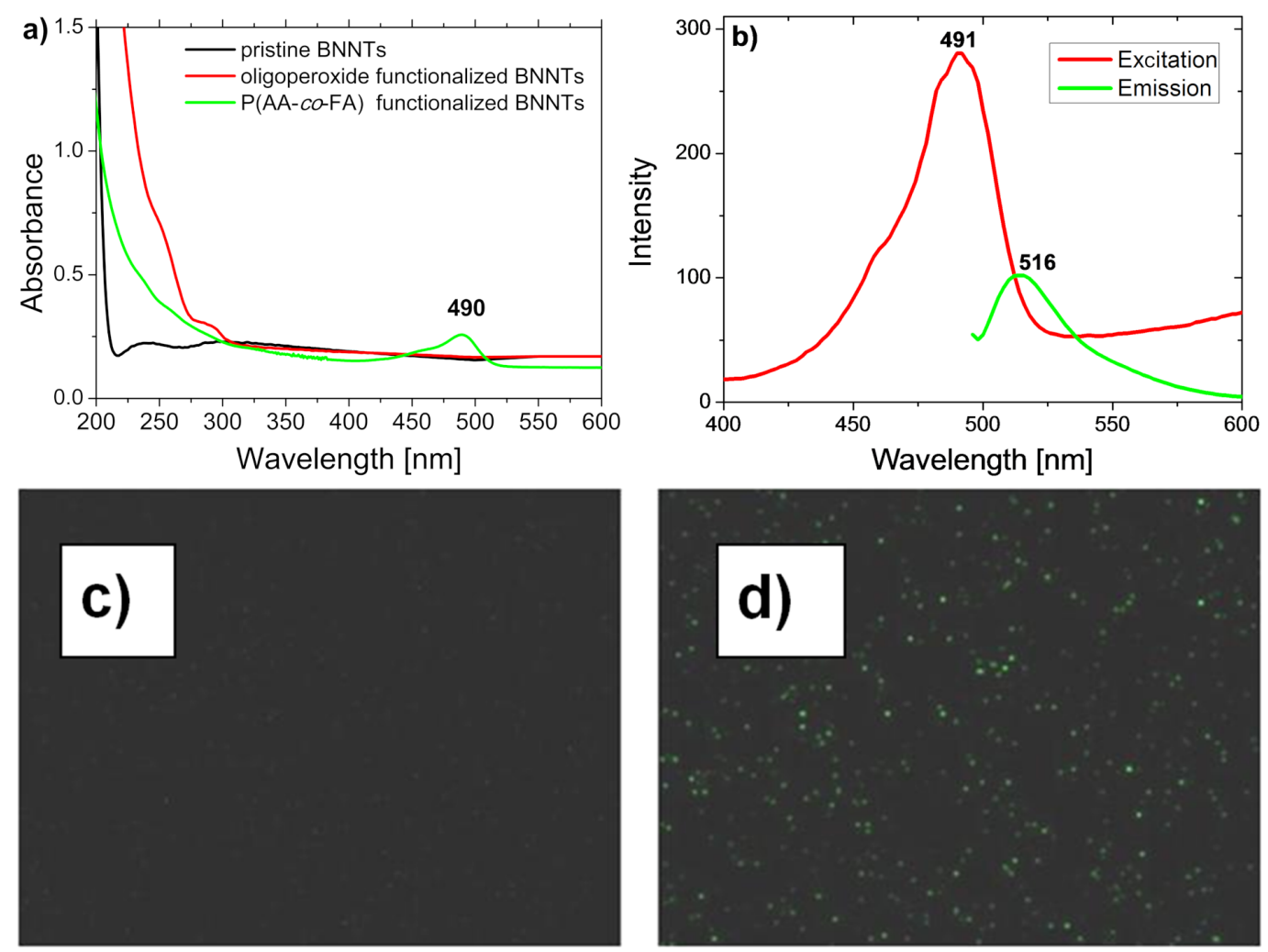

Figure 4: UV-vis spectra of BNNTs, oligoperoxide-functionalized BNNTs and $P(A A-c o-F A)$-functionalized BNNTs (a) and fluorescence of $P(A A-c o-$ FA)-functionalized BNNTs (b). Laser scanning confocal microscope images of pure BNNT (c) and P(AA-co-FA)-functionalized BNNTs (d). 
shows the absorption spectra of BNNTs, oligoperoxide-functionalized BNNTs, and $\mathrm{P}(\mathrm{AA}-\mathrm{co}-\mathrm{FA})$-functionalized BNNTs dispersed in water. $\mathrm{P}(\mathrm{AA}-\mathrm{co}-\mathrm{FA})$-functionalized BNNTs demonstrate a strong absorption band at $\lambda=490 \mathrm{~nm}$, which is very close to the maximum adsorption peak of fluorescein. However, the pristine BNNTs and the oligoperoxide-functionalized BNNTs do not have absorption in this region.

Figure $4 \mathrm{~b}$ shows the result of the fluorescence scanning of the $\mathrm{P}(\mathrm{AA}-\mathrm{co}$-FA)-functionalized BNNTs. The fluorescence spectra of the $\mathrm{P}(\mathrm{AA}-\mathrm{co}-\mathrm{FA})$-functionalized BNNTs retain the excitation maxima at $491 \mathrm{~nm}$ and the emission maximum at $516 \mathrm{~nm}$, which is in good agreement with the literature [49]. In contrast to "pure" BNNTs, where fluorescence is absent (Figure 4c), $\mathrm{P}(\mathrm{AA}-\mathrm{co}$-FA)-functionalized BNNTs (Figure 4d) demonstrate intense green fluorescence emission at $520 \mathrm{~nm}$. The fluorescence spectra of the $\mathrm{P}(\mathrm{AA}-\mathrm{co}-\mathrm{FA})$-functionalized BNNTs is important evidence for the grafting of $\mathrm{P}(\mathrm{AA}-\mathrm{co}-\mathrm{FA})$ on the BNNTs. These fluorescence properties are due to the $\pi-\pi^{*}$ transition in covalently bonded FA (chromophore) units of P(AAco-FA)-functionalized BNNTs.

SEM images of pure and P(AA-co-FA)-functionalized BNNTs after dispersion in water and drying on the surface are presented in Figure 5. The pristine BNNTs form large aggregates of several micrometers (Figure 5a). In contrast, the P(AA-co-FA)functionalized BNNTs are highly dispersed in water and only single nanotubes are visible (Figure $5 \mathrm{~b}$ ). The size-distribution profile (Figure 6) and zeta potential of BNNTs and P(AA-coFA)-functionalized BNNTs in water were also studied. P(AAco-FA)-functionalized BNNTs demonstrate a smaller $Z$-average diameter than the native BNNTs. The zeta potentials of
BNNTs and P(AA-co-FA)-functionalized BNNTs are -19.4 and $-14.3 \mathrm{mV}$, respectively. The zeta potential of $-17.7 \mathrm{mV}$ found for the BNNTs modified by oligoperoxide is only slightly smaller than that of "native" BNNTs. The zeta potential value for BNNTs is completely in agreement with our previous result [50]. However, oligoperoxide and P(AA-co-FA) have numerous carboxylic groups in their structure and one can expect significant change upon functionalization. This drastic change can be explained by the physical coverage of the functional group in the polymeric structure during functionalization.

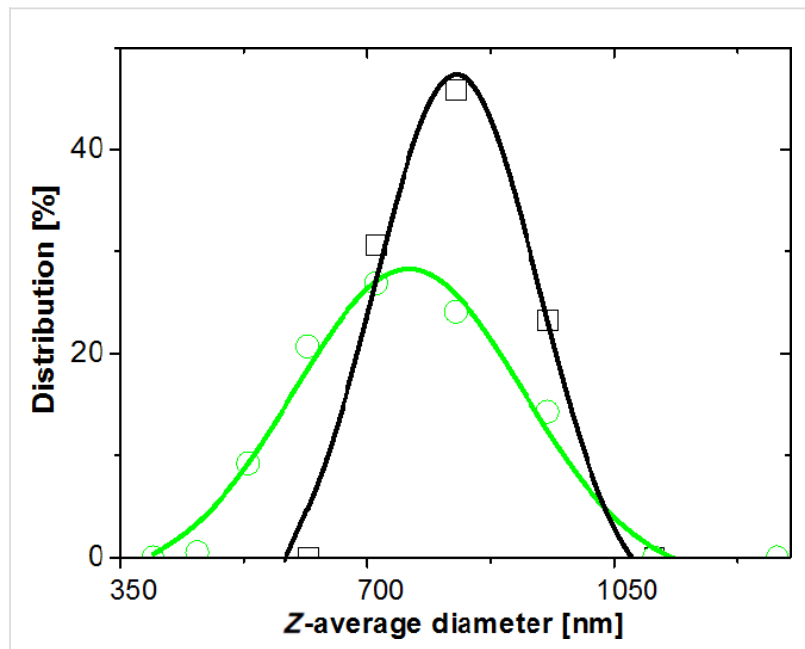

Figure 6: Size-distribution profile of BNNTs (black squares) and P(AAco-FA)-functionalized BNNTs (green circles) in water. The concentration in the distilled water was $1 \mathrm{mg} / \mathrm{mL}$.

In light of these results, we can state that $\mathrm{P}(\mathrm{AA}-\mathrm{co}$-FA)-functionalized BNNTs exhibit good dispersibility in water and their
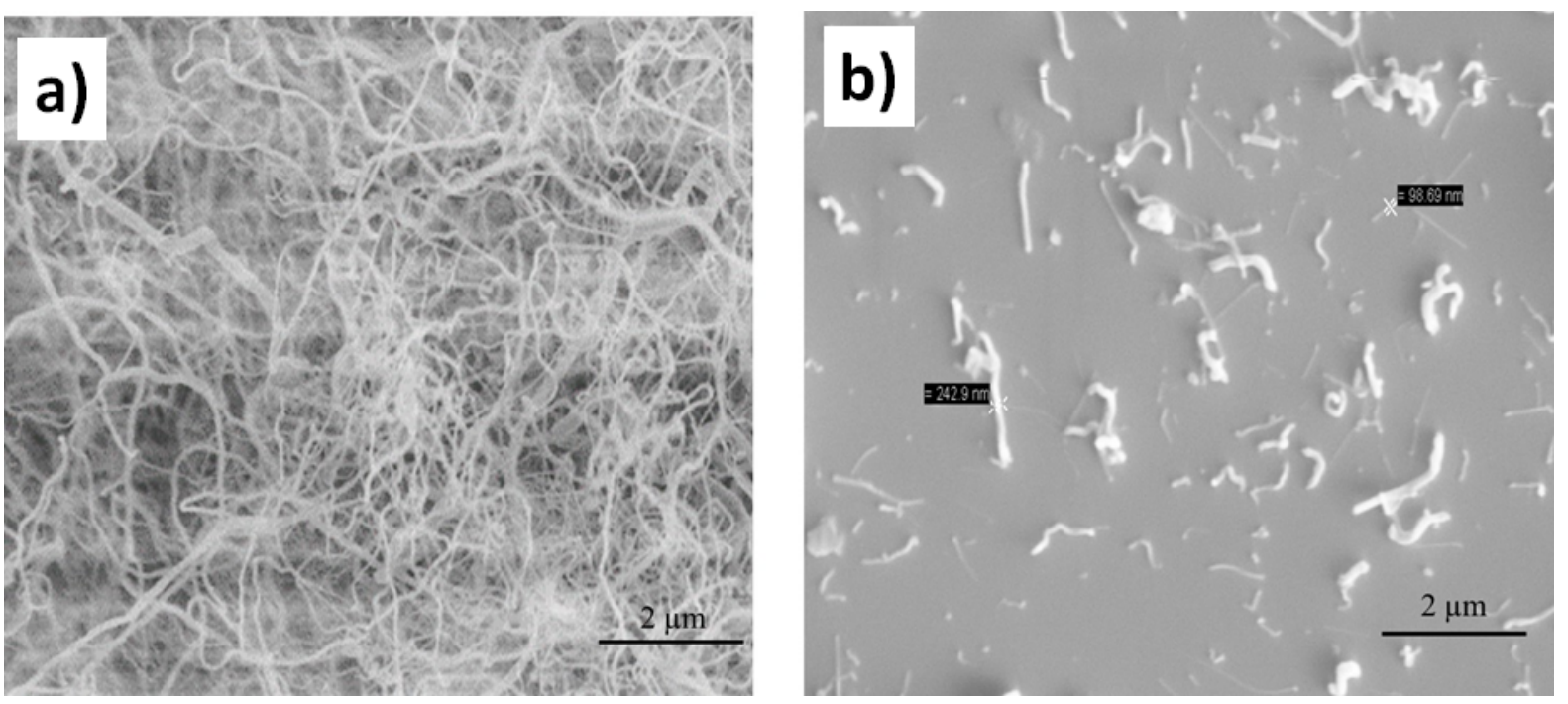

Figure 5: SEM image of pristine BNNTs (a) and P(AA-co-FA)-functionalized BNNTs (b) after dispersion in water. 
fluorescent properties make them excellent candidates for biomedical applications.

\section{$\mathrm{pH}$-Responsive fluorescent properties of $\mathrm{P}(\mathrm{AA}-\mathrm{co}-\mathrm{FA})$-functionalized BNNTs}

Depending on $\mathrm{pH}$, fluorescein can exist as a cation, monoanion, dianion, amphoion, neutral quinoid structure or neutral lactonic molecule [51]. Fluorescein monoacrylate, similar to fluorescein, can also form different molecular states (Scheme 2) depending upon pH [49,52]. Neutral and anionic forms of FMA units are responsible for fluorescence emission, but not the cationic form $[51,52]$. Fluorescein in a copolymer of hybrid P(AA-co-FA)BNNT can be expected to show switching properties depending on $\mathrm{pH}$.

Figure 7 shows the UV-vis spectra of a water-dispersed P(AAco-FA)-functionalized BNNTs at various $\mathrm{pH}$ values. All samples have the same concentration. It is known from the literature [51] that in acidic media the maximum fluorescein absorption is at $437 \mathrm{~nm}$ but in alkaline solution it is at about $490 \mathrm{~nm}$, and the absorption intensity is significantly higher than that of the acidic solution. As seen in the figure, the highest intensity of the absorbance is at $490 \mathrm{~nm}$ for $\mathrm{pH} 10$ (Figure 7, green line) and slightly less at $\mathrm{pH} 7-8$ (Figure 7, blue and red lines). In

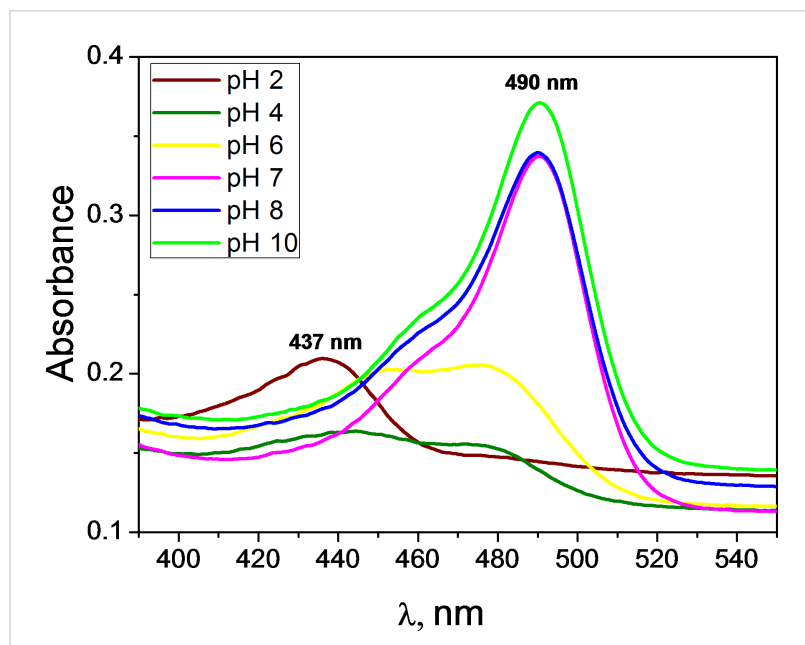

Figure 7: UV-vis spectra of a water suspension of $\mathrm{P}(\mathrm{AA}-\mathrm{CO}-\mathrm{FA})$-functionalized BNNTs $(1 \mathrm{mg} / \mathrm{mL})$ at various $\mathrm{pH}$ values.

contrast, at pH 6 (Figure 7, yellow line) a strongly shifted, small, intense absorbance peak is observed. At pH 4 (Figure 7 , green line) the absorbance is very poor, and we can state here that it has no absorbance. Only at pH 2 (Figure 7, brown line) do we observe a maximum fluorescein absorption at $437 \mathrm{~nm}$ [51].<smiles></smiles><smiles>C=CC(=O)Oc1ccc2c(-c3ccccc3C(=O)O)c3ccc(=O)cc-3oc2c1</smiles><smiles>C=CC(=O)Oc1ccc2c(-c3ccccc3C(=O)[O-])c3ccc(=O)cc-3oc2c1</smiles> 
The typical fluorescence spectra of $\mathrm{P}(\mathrm{AA}-\mathrm{co}-\mathrm{FA})$-functionalized BNNTs at various $\mathrm{pH}$ at different $\mathrm{pH}$ values are shown in Supporting Information File 1, Figure S1. The experiments were performed in the $\mathrm{pH}$ range of 2 to 10 . Figure 8 shows the fluorescence intensity of $\mathrm{P}(\mathrm{AA}-\mathrm{co}$-FA)-functionalized BNNTs. Under acidic conditions ( $\mathrm{pH} 2-6$ ), fluorescence molecules exist in neutral form and the emission spectra peaks of the $\mathrm{P}(\mathrm{AA}-\mathrm{co}$ FA)-functionalized BNNTs are absent or of extremely low intensity (see Figure 8 and Figure S1 in Supporting Information File 1). Under neutral or alkaline $\mathrm{pH}$ values $(\mathrm{pH} 7-10)$, the $\mathrm{P}(\mathrm{AA}-\mathrm{co}$-FA)-functionalized BNNTs are highly emissive, corresponding to the conjugated anionic form of the fluorescein monoacrylate molecule. The carboxylic group of fluorescein at neutral or alkaline $\mathrm{pH}$ values are deprotonated and become monoanionic fluorescein monoacrylate, whose electron density of the conjugated system for fluorescein molecules is very much enhanced, causing the fluorescence quantum yield to be much higher than that at acidic $\mathrm{pH}$ values [49]. No increase in the absorption intensity was observed for $\mathrm{P}(\mathrm{AA}-c o-\mathrm{FA})$-functionalized BNNTs when the $\mathrm{pH}$ was elevated from 7 to 10 , showing that the highest possible amount of the anionic form of fluorescein monoacrylate was reached at around $\mathrm{pH} 7$.

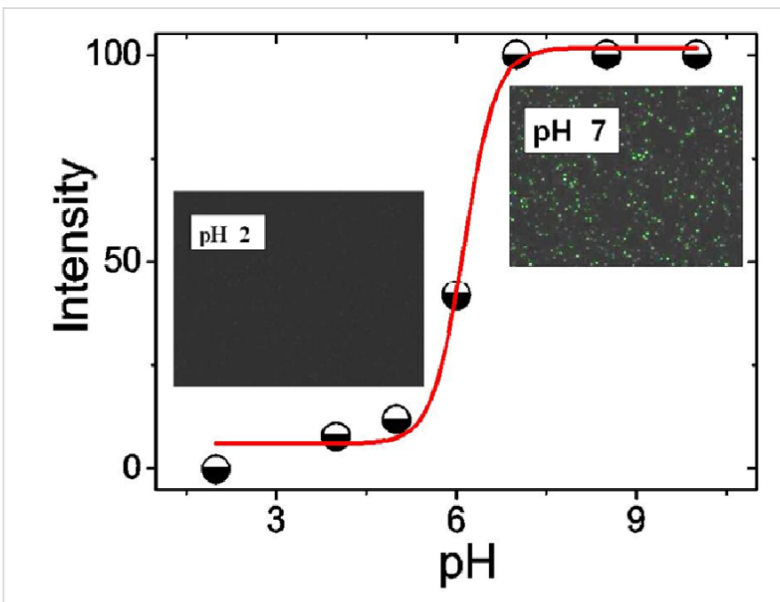

Figure 8: Fluorescence intensity of $\mathrm{P}(\mathrm{AA}-\mathrm{co}-\mathrm{FA})$-functionalized BNNTs in solution under different $\mathrm{pH}$ conditions. The fluorescence intensity was measured in distilled water and the $\mathrm{pH}$ was adjusted by adding $\mathrm{HCl}$ or $\mathrm{NaOH}$. The $\mathrm{P}(\mathrm{AA}-\mathrm{co}-\mathrm{FA})$-functionalized BNNT concentration in the solution was $(1 \mathrm{mg} / \mathrm{mL})$. The images demonstrate the fluorescence intensity in the dry state at different $\mathrm{pH}$ values recorded by LSCM. Excitation wavelength $-490 \mathrm{~nm}$, emission wavelength $520 \mathrm{~nm}$.

We can assume that the influence of the $\mathrm{pH}$-dependent changes of the conformation of the acrylic units in $\mathrm{P}(\mathrm{AA}-\mathrm{co}-\mathrm{FA})$-grafted brushes on the fluorescent properties is rather weak in this system. The crucial role in $\mathrm{pH}$-controlled switching of fluoresce belongs to the transformation of the fluorescein monoacrylate units from cationic form to neutral, and especially anionic forms. The conformation of the poly(acrylic acid) chain at acidic $\mathrm{pH}$ is not a collapsed structure and remains soluble in water [53]. However, $\mathrm{pH}$-dependent changes of the conformation of the acrylic units in $\mathrm{P}(\mathrm{AA}-\mathrm{co}-\mathrm{FA})$-grafted brushes can have a strong influence on the dispersibility of the functionalized-BNNTs in water. For acidic $\mathrm{pH}$ values, intermolecular aggregation of poly(acrylic acid) due to hydrophobic interactions was shown [54]. At neutral or basic $\mathrm{pH}$, the hydrodynamic diameter of the poly(acrylic acid) macromolecules was significantly decreased, indicating the disruption of intermolecular aggregates [54].

\section{Cellular imaging using P(AA-co-FA)-functionalized BNNTs}

Fluorescence microscopy of living cells has become an integral part of modern cell biology. Most often cellular imaging is provided using fluorescent labels, including fluorescent dyes, nanoparticles, nanocomposites or proteins [55]. This label must meet certain criteria, such as biocompatibility, molecular recognition, chemical stability, and ability to be taken up in cells, etc. [55].

It is known that in living cells, both $\mathrm{pH}$ and temperature fluctuations are experienced during cellular processes such as endosytosis, gene expression, enzymatic reactions and metabolism [56,57]. Abnormal intracellular $\mathrm{pH}$ values are often associated with cell dysfunction and are observed in diseases such as cancer [58] and Alzheimer's [59]. Therefore, information on intracellular $\mathrm{pH}$ is a crucial factor in understanding the physiological and pathological processes within living cells.

In our previous work, BNNTs were tested for their delivery potential, which showed promising results for imaging and drug targeting applications $[60,61]$. As a continuation of the work $[60,61]$, we demonstrate the potential of BNNTs as a novel $\mathrm{pH}$-switchable fluorescent water-dispersed material for cellular imaging.

To study the uptake of P(AA-co-FA)-functionalized BNNTs into human normal prostate epithelium (PNT1A) and human prostate cancer (DU145) cell lines, we used fluorescence microscopy with excitation at $490 \mathrm{~nm}$ and emission at $520 \mathrm{~nm}$ (Figure 9). The autofluorescence of healthy cells and cancer cells was strictly avoided. DU145 cells internalize more P(AAco-FA)-functionalized BNNTs because of their higher nutrition requirement for their fast proliferation and growth. While only P(AA-co-FA)-functionalized BNNT labeled cell nuclei were detectable in PNT1A control cells, the cells incubated with P(AA-co-FA)-functionalized BNNTs clearly showed fluorescence not only in the nuclei but also in the cytosol. The reason for this is likely due to the more internalized material compared to the healthy cells as a result of higher metabolic activity of cancer cells. This study clearly shows that the cellular uptake of 

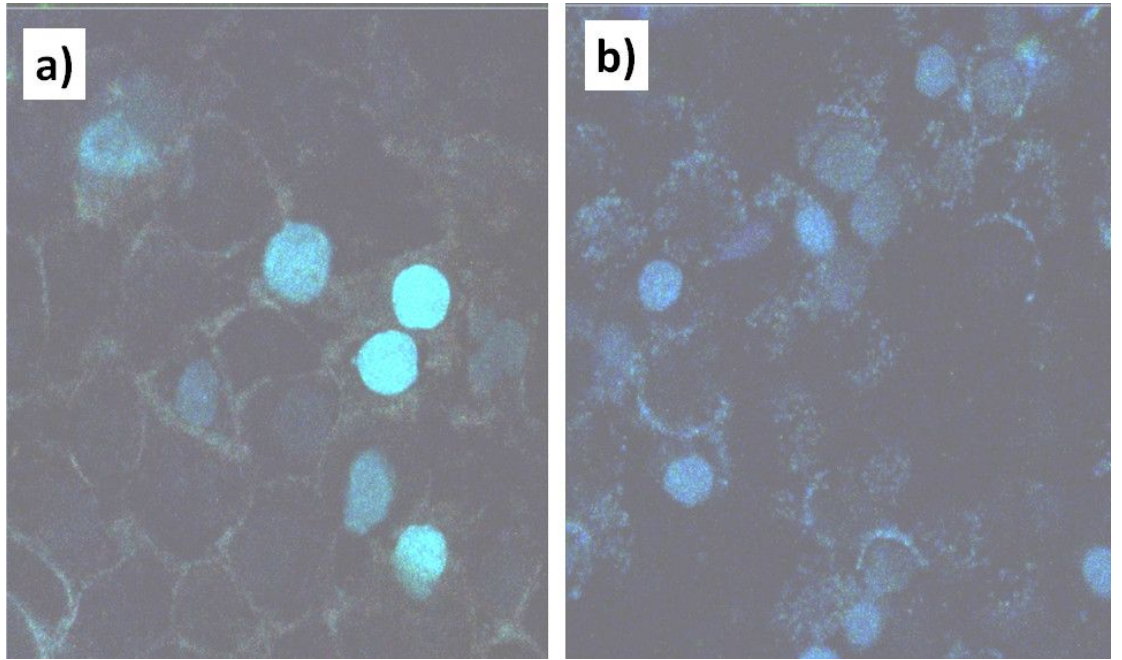

Figure 9: Fluorescent images recorded for human normal prostate epithelium cellular line (PNT1A) (a) and human prostate cancer cellular line (DU145) (b) with uptake of P(AA-co-FA)-functionalized BNNTs. Excitation wavelength: $490 \mathrm{~nm}$; emission wavelength: $520 \mathrm{~nm}$.

$\mathrm{P}(\mathrm{AA}-\mathrm{co}$-FA)-functionalized BNNTs is excellent and they can potentially be used in biomedical applications. We plan to continue to explore this new hybrid in our future studies not only as a pH-switchable label but also as "smart" surfaces and nanocarriers.

\section{Conclusion}

$\mathrm{pH}-\mathrm{S}$ witchable, fluorescent, hybrid, water-dispersed nanomaterials based on BNNTs and grafted brushes of copolymer P(AAco-FA) were successfully fabricated in a two-step process and have several distinct advantages. First, the functionalized BNNTs in contrast to "native" BNNTs are highly dispersible in water. Second, the functionalized BNNTs demonstrate $\mathrm{pH}$-dependent fluorescence properties. Third, acrylic groups in P(AAco-FA) can be easy modified for drugs and/or targeting agents similar to that reported in [61]. It is well known that the carboxyl group of acrylic acid can react with ammonia to form acrylamide, or with an alcohol to form an acrylate ester. Moreover, the carboxyl group is able to create ionic bonds with numerous chemicals. In addition, it was shown that functionalized BNNTs are easily taken up by cells and could be considered as promising nanomaterials for cellular imaging and beyond.

The functionalized BNNTs were characterized using spectroscopic, gravimetric and imaging techniques, including FTIR, UV-vis, DLS, TGA, LSCM and SEM. The data clearly confirmed the functionalization of BNNTs with $\mathrm{P}(\mathrm{AA}-\mathrm{co}-\mathrm{FA})$. In contrast to "pure" BNNTs, P(AA-co-FA)-functionalized BNNTs demonstrate an intense green emission at $520 \mathrm{~nm}$. Moreover, the $\mathrm{pH}$-switchable fluorescence of the obtained BNNTs was previously described for fluorescein $[46,49,51]$ and fluorescein-containing polymers [42,52]. Under neutral or alka- line $\mathrm{pH}$ values ( $\mathrm{pH} 7-10)$, the $\mathrm{P}(\mathrm{AA}-\mathrm{co}-\mathrm{FA})$-functionalized BNNTs are highly emissive, corresponding to the conjugated anionic form of fluorescein monoacrylate molecule. The carboxylic group of fluorescein at neutral or alkaline $\mathrm{pH}$ are deprotonated, forming monoanionic fluorescein monoacrylate, whose electron density of the conjugated system for fluorescein molecules is very much enhanced resulting in much higher quantum yield than that under acidic $\mathrm{pH}$ values [49]. No increase in the absorption intensity was observed for P(AA-coFA)-functionalized BNNTs when the $\mathrm{pH}$ was elevated from 7 to 10 , indicating that the highest possible concentration of the anionic form of fluorescein monoacrylate was reached at around $\mathrm{pH} 7$.

Finally, P(AA-co-FA)-functionalized BNNTs were tested as a fluorescent label for cellular imaging. The functionalized BNNTs were easily taken up by PNT1A and DU145 cells and demonstrated good fluorescence properties. We concluded that P(AA-co-FA)-graft-oligoperoxide functionalized waterdispersed $\mathrm{pH}$-switchable fluorescent BNNTs have great potential in biomedical applications as "smart" surfaces, nanocarriers and fluorescent labels.

\section{Supporting Information}

\section{Supporting Information File 1}

Fluorescence scanning (typical excitation and emission spectra) of P(AA-co-FM)-functionalized BNNTs under different $\mathrm{pH}$ conditions.

[https://www.beilstein-journals.org/bjnano/content/ supplementary/2190-4286-10-233-S1.pdf] 


\section{Acknowledgements}

We thank Prof. Volodymyr Lobaz from the Institute of Macromolecular Chemistry AS CR, Prague, Czech Republic for fruitful discussion and valuable suggestions.

\section{ORCID ${ }^{\circledR}$ iDs}

Saban Kalay - https://orcid.org/0000-0002-9363-0073

Yurij Stetsyshyn - https://orcid.org/0000-0002-6498-2619

\section{References}

1. Cavallaro, G.; Lazzara, G.; Milioto, S.; Parisi, F.; Evtugyn, V.; Rozhina, E.; Fakhrullin, R. ACS Appl. Mater. Interfaces 2018, 10 , 8265-8273. doi:10.1021/acsami.7b19361

2. Prishchenko, D. A.; Zenkov, E. V.; Mazurenko, V. V.; Fakhrullin, R. F.; Lvov, Y. M.; Mazurenko, V. G. Phys. Chem. Chem. Phys. 2018, 20 , 5841-5849. doi:10.1039/c7cp06575b

3. Fakhrullin, R. F.; Lvov, Y. M. Nanomedicine (London, U. K.) 2016, 11, 2243-2246. doi:10.2217/nnm-2016-0250

4. Yendluri, R.; Lvov, Y.; de Villiers, M. M.; Vinokurov, V.; Naumenko, E.; Tarasova, E.; Fakhrullin, R. J. Pharm. Sci. 2017, 106, 3131-3139. doi:10.1016/j.xphs.2017.05.034

5. Stetsyshyn, Y.; Awsiuk, K.; Kusnezh, V.; Raczkowska, J.; Jany, B. R.; Kostruba, A.; Harhay, K.; Ohar, H.; Lishchynskyi, O.; Shymborska, Y.; Kryvenchuk, Y.; Krok, F.; Budkowski, A. Appl. Surf. Sci. 2019, 463, 1124-1133. doi:10.1016/j.apsusc.2018.09.033

6. Cavallaro, G.; Lazzara, G.; Lisuzzo, L.; Milioto, S.; Parisi, F. Nanotechnology 2018, 29, 325702. doi:10.1088/1361-6528/aac5c3

7. Cavallaro, G.; Lazzara, G.; Massaro, M.; Milioto, S.; Noto, R.; Parisi, F.; Riela, S. J. Phys. Chem. C 2015, 119, 8944-8951. doi:10.1021/acs.jpcc.5b00991

8. Stetsyshyn, Y.; Raczkowska, J.; Budkowski, A.; Awsiuk, K.; Kostruba, A.; Nastyshyn, S.; Harhay, K.; Lychkovskyy, E.; Ohar, H.; Nastishin, Y. Langmuir 2016, 32, 11029-11038. doi:10.1021/acs.langmuir.6b02946

9. Raczkowska, J.; Stetsyshyn, Y.; Awsiuk, K.; Lekka, M.; Marzec, M.; Harhay, K.; Ohar, H.; Ostapiv, D.; Sharan, M.; Yaremchuk, I.; Bodnar, Y.; Budkowski, A. Appl. Surf. Sci. 2017, 407, 546-554. doi:10.1016/j.apsusc.2017.03.001

10. Marchenko, I.; Yashchenok, A.; German, S.; Inozemtseva, O.; Gorin, D.; Bukreeva, T.; Mohwald, H.; Skirtach, A. Polymers (Basel, Switz.) 2010, 2, 690-708. doi:10.3390/polym2040690

11. Lisuzzo, L.; Cavallaro, G.; Lazzara, G.; Milioto, S.; Parisi, F.; Stetsyshyn, Y. Appl. Sci. 2018, 8, 1068. doi:10.3390/app8071068

12. Kalay, S.; Stetsyshyn, Y.; Lobaz, V.; Harhay, K.; Ohar, H.; Çulha, M. Nanotechnology 2016, 27, 035703. doi:10.1088/0957-4484/27/3/035703

13. Ciofani, G.; Genchi, G. G.; Liakos, I.; Athanassiou, A.; Dinucci, D.; Chiellini, F.; Mattoli, V. J. Colloid Interface Sci. 2012, 374, 308-314. doi:10.1016/j.jcis.2012.01.049

14. Ciofani, G.; Danti, S.; Ricotti, L.; D'Alessandro, D.; Moscato, S.; Berrettini, S.; Mattoli, V.; Menciassi, A. Curr. Nanosci. 2011, 7, 94-109. doi:10.2174/157341311794480345

15. Genchi, G. G.; Ciofani, G. Nanomedicine (London, U. K.) 2015, 10 , 3315-3319. doi:10.2217/nnm.15.148

16. Rocca, A.; Marino, A.; Del Turco, S.; Cappello, V.; Parlanti, P.; Pellegrino, M.; Golberg, D.; Mattoli, V.; Ciofani, G. Biochim. Biophys. Acta, Gen. Subj. 2016, 1860, 775-784. doi:10.1016/j.bbagen.2016.01.020
17. lijima, S. Nature 1991, 354, 56-58. doi:10.1038/354056a0

18. Yang, G.; Yang, X.; Yang, C.; Yang, Y. Colloids Surf., A 2011, 389, 195-200. doi:10.1016/j.colsurfa.2011.08.027

19. Lai, Y.; Huang, Y.; Wang, H.; Huang, J.; Chen, Z.; Lin, C. Colloids Surf., B 2010, 76, 117-122. doi:10.1016/j.colsurfb.2009.10.023

20. Chopra, N. G.; Luyken, R. J.; Cherrey, K.; Crespi, V. H.; Cohen, M. L.; Louie, S. G.; Zettl, A. Science 1995, 269, 966-967. doi:10.1126/science.269.5226.966

21. Suryavanshi, A. P.; Yu, M.-F.; Wen, J.; Tang, C.; Bando, Y. Appl. Phys. Lett. 2004, 84, 2527-2529. doi:10.1063/1.1691189

22. Zhi, C.; Bando, Y.; Tang, C.; Xie, R.; Sekiguchi, T.; Golberg, D. J. Am. Chem. Soc. 2005, 127, 15996-15997. doi:10.1021/ja053917c

23. Terao, T.; Zhi, C.; Bando, Y.; Mitome, M.; Tang, C.; Golberg, D. J. Phys. Chem. C 2010, 114, 4340-4344. doi:10.1021/jp911431f

24. Chopra, N. G.; Zettl, A. Solid State Commun. 1998, 105, 297-300. doi:10.1016/s0038-1098(97)10125-9

25. Kalay, S.; Yilmaz, Z.; Sen, O.; Emanet, M.; Kazanc, E.; Çulha, M. Beilstein J. Nanotechnol. 2015, 6, 84-102. doi:10.3762/bjnano.6.9

26. Gao, Z.; Zhi, C.; Bando, Y.; Golberg, D.; Serizawa, T. Functionalization of boron nitride nanotubes for applications in nanobiomedicine. In Boron Nitride Nanotubes in Nanomedicine; Ciofani, G.; Mattoli, V., Eds.; Elsevier: Amsterdam, Netherlands, 2016; pp 17-40. doi:10.1016/b978-0-323-38945-7.00002-x

27. Gao, Z.; Zhi, C.; Bando, Y.; Golberg, D.; Serizawa, T. Nanobiomedicine 2014, 1, 7. doi: $10.5772 / 60000$

28. Ejaz, M.; Rai, S. C.; Wang, K.; Zhang, K.; Zhou, W.; Grayson, S. M. J. Mater. Chem. C 2014, 2, 4073-4079. doi:10.1039/c3tc32511c

29. Zhang, J.; Campbell, R. E.; Ting, A. Y.; Tsien, R. Y. Nat. Rev. Mol. Cell Biol. 2002, 3, 906-918. doi:10.1038/nrm976

30. Gao, X.; Yang, L.; Petros, J. A.; Marshall, F. F.; Simons, J. W.; Nie, S. Curr. Opin. Biotechnol. 2005, 16, 63-72. doi:10.1016/j.copbio.2004.11.003

31. Fernández-Suárez, M.; Ting, A. Y. Nat. Rev. Mol. Cell Biol. 2008, 9 , 929-943. doi:10.1038/nrm2531

32. Breul, A. M.; Hager, M. D.; Schubert, U. S. Chem. Soc. Rev. 2013, 42, 5366-5407. doi:10.1039/c3cs35478d

33. Michalet, X.; Pinaud, F. F.; Bentolila, L. A.; Tsay, J. M.; Doose, S.; Li, J. J.; Sundaresan, G.; Wu, A. M.; Gambhir, S. S.; Weiss, S. Science 2005, 307, 538-544. doi:10.1126/science.1104274

34. Larson, D. R.; Zipfel, W. R.; Williams, R. M.; Clark, S. W.; Bruchez, M. P.; Wise, F. W.; Webb, W. W. Science 2003, 300, 1434-1436. doi:10.1126/science. 1083780

35. Volkmann, M.; Meyns, M.; Lesyuk, R.; Lehmann, H.; Klinke, C. Chem. Mater. 2017, 29, 726-734. doi:10.1021/acs.chemmater.6b04497

36. Massaro, M.; Colletti, C. G.; Guernelli, S.; Lazzara, G.; Liu, M.; Nicotra, G.; Noto, R.; Parisi, F.; Pibiri, I.; Spinella, C.; Riela, S. J. Mater. Chem. C 2018, 6, 7377-7384. doi:10.1039/c8tc01424h

37. Rowe, M. D.; Thamm, D. H.; Kraft, S. L.; Boyes, S. G. Biomacromolecules 2009, 10, 983-993. doi:10.1021/bm900043e

38. Ding, L.; Jani, D.; Linhardt, J.; Künzler, J. F.; Pawar, S.; Labenski, G.; Smith, T.; Knox, W. H. J. Opt. Soc. Am. B 2009, 26, 1679-1687. doi:10.1364/josab.26.001679

39. Hoshino, Y.; Koide, H.; Urakami, T.; Kanazawa, H.; Kodama, T.; Oku, N.; Shea, K. J. J. Am. Chem. Soc. 2010, 132, 6644-6645. doi:10.1021/ja102148f

40. Srisopa, A.; Imroz Ali, A. M.; Mayes, A. G. J. Polym. Sci., Part A: Polym. Chem. 2011, 49, 2070-2080. doi:10.1002/pola.24636 
41. Govindaiah, P.; Hwang, T.; Yoo, H.; Kim, Y. S.; Lee, S. J.; Choi, S. W.; Kim, J. H. J. Colloid Interface Sci. 2012, 379, 27-32. doi:10.1016/j.jcis.2012.04.055

42. Nese, A.; Lebedeva, N. V.; Sherwood, G.; Averick, S.; Li, Y.; Gao, H.; Peteanu, L.; Sheiko, S. S.; Matyjaszewski, K. Macromolecules 2011, 44, 5905-5910. doi:10.1021/ma201045c

43. Ikuno, T.; Sainsbury, T.; Okawa, D.; Fréchet, J. M. J.; Zettl, A. Solid State Commun. 2007, 142, 643-646. doi:10.1016/j.ssc.2007.04.010

44. Lin, Y.; Williams, T. V.; Cao, W.; Elsayed-Ali, H. E.; Connell, J. W. J. Phys. Chem. C 2010, 114, 17434-17439. doi:10.1021/jp105454w

45. Sundaram, R.; Scheiner, S.; Roy, A. K.; Kar, T. J. Phys. Chem. C 2015, 119, 3253-3259. doi:10.1021/jp512753n

46. Riddick, J.; Bunger, W.; Sakano, T. Organic solvents: physical properties and methods of purification, 4th ed.; 1986.

47. Milas, N. A.; Surgenor, D. M. J. Am. Chem. Soc. 1946, 68, 205-208. doi:10.1021/ja01206a017

48. Allgemeine Laboratoriumspraxis, 4th ed.; Methoden der Organischen Chemie (Houben-Weyl), Vol. 1; Georg Thieme Verlag: Stuttgart, Germany, 1958. doi:10.1055/b-003-115783

49. Song, A.; Zhang, J.; Zhang, M.; Shen, T.; Tang, J. Colloids Surf., A 2000, 167, 253-262. doi:10.1016/s0927-7757(99)00313-1

50. Şen, Ö.; Emanet, M.; Çulha, M. Front. Bioeng. Biotechnol. 2018, 6, 83. doi:10.3389/fbioe.2018.00083

51. Martin, M. M.; Lindqvist, L. J. Lumin. 1975, 10, 381-390. doi:10.1016/0022-2313(75)90003-4

52. Govindaiah, P.; Lee, S. J.; Kim, J. H.; Cheong, I. W. Polymer 2011, 52, 5058-5064. doi:10.1016/j.polymer.2011.08.046

53. Swift, T.; Swanson, L.; Geoghegan, M.; Rimmer, S. Soft Matter 2016, 12, 2542-2549. doi:10.1039/c5sm02693h

54. Lee, H.-i.; Boyce, J. R.; Nese, A.; Sheiko, S. S.; Matyjaszewski, K. Polymer 2008, 49, 5490-5496. doi:10.1016/j.polymer.2008.10.001

55. Demchenko, A. P. Methods Appl. Fluoresc. 2013, 1, 022001. doi:10.1088/2050-6120/1/2/022001

56. Lowell, B. B.; Spiegelman, B. M. Nature 2000, 404, 652-660. doi:10.1038/35007527

57. Yamada, A.; Hiruta, Y.; Wang, J.; Ayano, E.; Kanazawa, H. Biomacromolecules 2015, 16, 2356-2362. doi:10.1021/acs.biomac.5b00591

58. Izumi, H.; Torigoe, T.; Ishiguchi, H.; Uramoto, H.; Yoshida, Y.; Tanabe, M.; Ise, T.; Murakami, T.; Yoshida, T.; Nomoto, M.; Kohno, K. Cancer Treat. Rev. 2003, 29, 541-549. doi:10.1016/s0305-7372(03)00106-3

59. Davies, T. A.; Fine, R. E.; Johnson, R. J.; Levesque, C. A.; Rathbun, W. H.; Seetoo, K. F.; Smith, S. J.; Strohmeier, G.; Volicer, L.; Delva, L.; Simons, E. R. Biochem. Biophys. Res. Commun. 1993, 194, 537-543. doi:10.1006/bbrc.1993.1853

60. Ciofani, G.; Raffa, V.; Menciassi, A.; Cuschieri, A. Nanoscale Res. Lett. 2009, 4, 113-121. doi:10.1007/s11671-008-9210-9

61. Emanet, M.; Şen, Ö.; Çulha, M. Nanomedicine (London, U. K.) 2017, 12, 797-810. doi:10.2217/nnm-2016-0322

\section{License and Terms}

This is an Open Access article under the terms of the Creative Commons Attribution License (http://creativecommons.org/licenses/by/4.0). Please note that the reuse, redistribution and reproduction in particular requires that the authors and source are credited.

The license is subject to the Beilstein Journal of Nanotechnology terms and conditions: (https://www.beilstein-journals.org/bjnano)

The definitive version of this article is the electronic one which can be found at:

doi:10.3762/bjnano.10.233 